\title{
Profilaxia reversa: o estigma da lepra do hospital para a cidade
}

\section{Reverse prophylaxis: the leprosy stigma from the hospital to the city}

\author{
Aline de Fátima Lapchensk ${ }^{a}$ \\ aPontifícia Universidade Católica do Paraná. Programa de Pós- \\ - Graduação em Gestão Urbana. Curitiba, PR, Brasil. \\ E-mail: aline.lapchenskळpucpr.br \\ Letícia Peret Antunes Hardt ${ }^{b}$ \\ 'Pontifícia Universidade Católica do Paraná. Programa de Pós- \\ - Graduação em Gestão Urbana. Curitiba, PR, Brasil. \\ E-mail: I.hardtळpucpr.br
}

\section{Resumo}

Os antecedentes históricos da hanseníase como problema social conduziram à construção de hospitais-colônia para isolamento de portadores da doença - uma medida profilática, a fim de evitar sua disseminação. Entretanto, esses estabelecimentos reforçaram o estigma da moléstia e perderam significado diante dos avanços científicos do tratamento ambulatorial. Assim, foram progressivamente descaracterizados, a exemplo do objeto deste estudo - o Hospital de Dermatologia Sanitária do Paraná, instalado em Piraquara, na região metropolitana de Curitiba. Com base nessa conjuntura, a pesquisa objetiva analisar as consequências da desativação de um complexo hospitalar, diagnosticando sua situação atual e refletindo sobre alternativas para minimização das suas interferências deletérias, contribuindo para o desenvolvimento do pensamento sobre outras experiências urbanísticas de organização do espaço social perante a estigmatização. A investigação foi baseada em técnicas de revisão de fontes bibliográficas e documentais sobre o tema e o objeto de estudo. Os resultados revelam que os retrocessos promoveram uma trajetória de segregação socioespacial e intraurbana, determinando necessidades de inclusão que demandam a constituição de políticas públicas de saúde associadas a diretrizes de gestão de cidades. Palavras-chave: Modelo Hospitalar; Estigma da Doença; Processo de Segregação; Hanseníase; Gestão Pública.

\section{Correspondência:}


The history of leprosy as a social problem led to the construction of colony hospitals for the isolation of the ill - a prophylaxis measure, in order to contain dissemination. However, these establishments have reinforced the disease stigma and have lost their meaning in the face of scientific advances in outpatient treatment. Thus, they were progressively mischaracterized, like the object of this study - the Hospital de Dermatologia Sanitária do Paraná, installed in Piraquara, Paraná, Brazil, in the metropolitan region of Curitiba. Based on this scenario, the research aims at analyzing the consequences of the deactivation of a hospital complex, diagnosing its current situation and reflecting on alternatives to minimize its deleterious interferences, contributing to the development of thinking about other urban experiences of organizing the social space in the face of stigmatization. The work was based on revision techniques of bibliographical and documentary sources on the subject and the object of study. The results show that the setbacks promoted a socio-spatial and intraurban segregation, determining the necessity of inclusion that demand the constitution of public health policies associated to city management guidelines.

Keywords: Hospital Model; Stigma of Illness; Process of Segregation; Hansen's disease; Public Management.
A hanseníase, também conhecida durante muito tempo como lepra, foi introduzida no Brasil logo após o descobrimento da terra pelos portugueses (Smith III, 2003). Com a predominância do higienismo no Brasil Republicano, o Poder Público objetivava estabelecer uma nova ordem social, na qual constava uma cidade saneada, organizada, saudável e produtiva, o que refletia desenvolvimento e progresso. Para essa finalidade, foram combatidas, além das epidemias, pelos seus riscos de contágio, as chamadas doenças sociais, isolando, excluindo e marginalizando loucos, criminosos, mendigos e crianças abandonadas (Castro, 2004). Venancio (2011) comenta, inclusive, que a origem do alienismo no país ocorreu em 1841, com a primeira instituição assistencial voltada para a alienação mental, associada à ideia do trabalho como terapêutica (Engel, 2001) e ao controle federal sobre as demais instâncias (Lima; Fonseca; Hochman, 2005).

Conforme relatam Schneider e Wadi (2009), o fato de a lepra ainda ser considerada problema social durante as primeiras décadas do século XX deu origem à construção de diversos hospitais-colônia no país, destinados ao isolamento de portadores das moléstias. As mesmas autoras explicam que essas instalações tinham configuração de pequenas cidades intramuros, com estrutura independente do município em que estavam inseridas. Hoje, o tratamento é ambulatorial, dispensando internamento; assim, esses estabelecimentos de saúde foram progressivamente descaracterizados. Dessa forma, os hospitais, que serviam de medidas profiláticas para o afastamento de doentes, passaram a sofrer os efeitos da segregação, no que se chama, neste estudo, de "profilaxia reversa".

Esse foi o caso do Hospital de Dermatologia Sanitária do Paraná (HDSPR), também designado como Colônia São Roque, objeto principal desta investigação. No seu entorno próximo, foram consolidados diversos bairros, constituídos por várias gerações de funcionários, ex-empregados, parentes, egressos e outros. Trata-se, porém, de região social e ambientalmente vulnerável, com problemas das mais diversas ordens. Diante da problemática 
relatada, o objetivo geral do estudo consiste em analisar as consequências da desativação do hospital, diagnosticando sua situação atual e refletindo sobre possíveis alternativas para a minimização de suas interferências deletérias, contribuindo para o desenvolvimento do pensamento sobre outras experiências urbanísticas de organização do espaço social perante a estigmatização.

\section{Procedimentos metodológicos}

A pesquisa foi baseada em técnicas da revisão de fontes bibliográficas e documentais sobre o tema e seu objeto. 0 método adotado foi apoiado no estudo de caso detalhado pela análise situacional, na qual ocorre a "tentativa de incorporar um conflito como sendo 'normal' em lugar de parte 'anormal' do processo social” (Van Velsen, 2010, p. 345). Conforme aponta Feldman-Bianco (2010), utiliza, nesse contexto, registros de acontecimentos concretos e do comportamento de indivíduos específicos como constituintes da interpretação de situações a partir da coleta de exemplos interconectados em determinada área no decurso do tempo.

Assim, a investigação foi respaldada na observação sistemática do HDSPR, a fim de serem desvendados o desenvolvimento e as mudanças das relações em seu contexto social e cultural ao longo de sua história, além de compreender pontos de vista de diferentes grupos de interesse. Instalado na região metropolitana de Curitiba, especificamente no território municipal de Piraquara, o hospital foi inaugurado em 20 de outubro de 1926, durante o governo de Caetano Munhoz da Rocha, no período denominado Primeira República, de 1889 a 1930 (Castro, 2005). Seu terreno de 100 ha, pertencente anteriormente à Fazenda Campina, localizada no município então chamado Deodoro, dista cerca de $20 \mathrm{~km}$ da capital (Figuras 1 e 2).

O crescimento da malha urbana ao redor do hospital não foi necessariamente ordenado. Atualmente, a grande área pertencente à instituição, além de inerte em meio a uma localidade cercada de carências, representa importante barreira física para as circunvizinhanças (Lapchensk, 2017).

\section{Figura I - Localização do Hospital de Dermatologia Sanitária do Paraná na região metropolitana de Curitiba (esquerda) e no município de Piraquara (direita)}

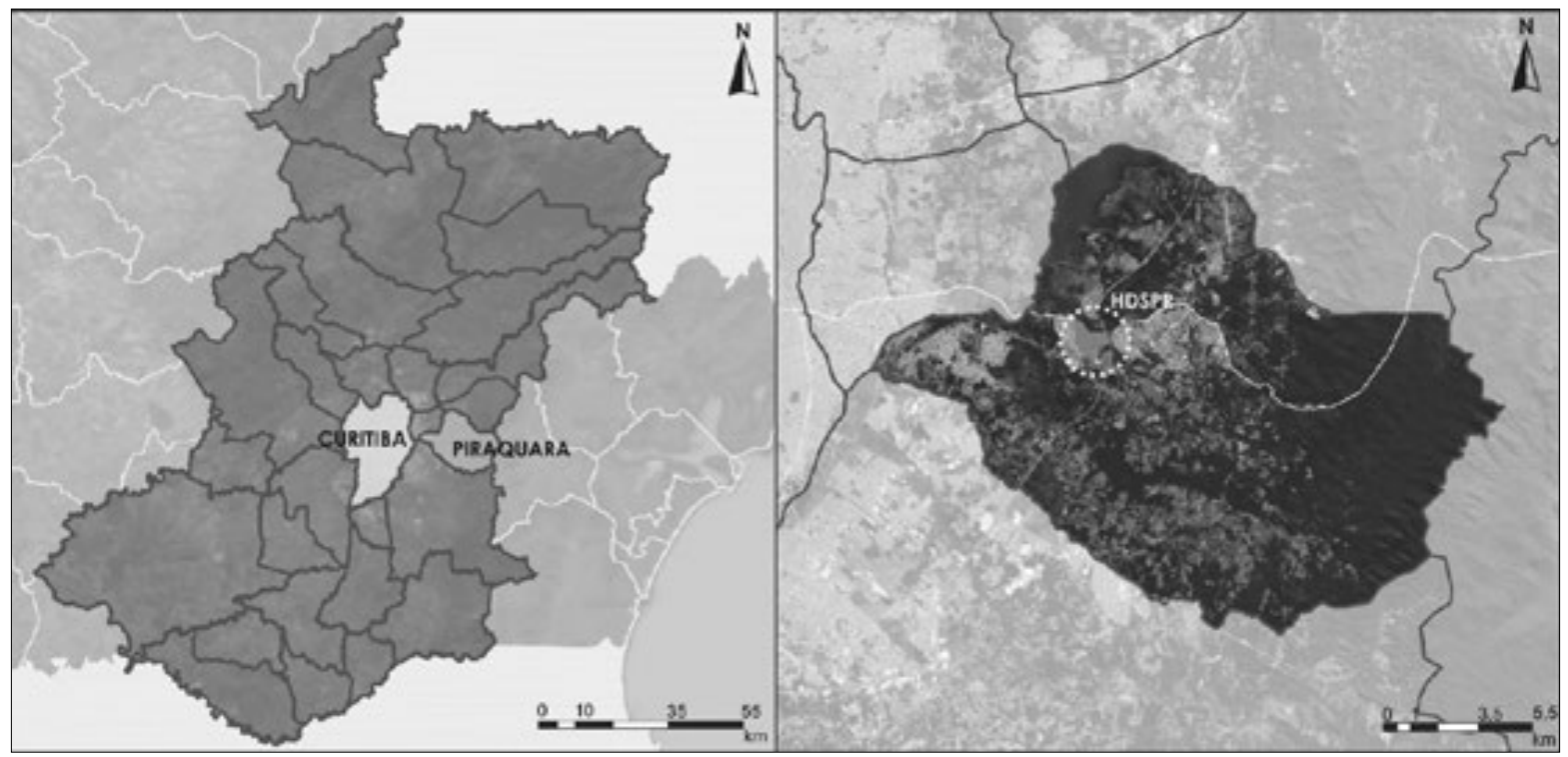

Fonte: Adaptadas de Paraná' e Google Earth²

I PARANÁ. Coordenação da Região Metropolitana de Curitiba. Região Metropolitana de Curitiba, Curitiba, fev. 2017. Disponível em: <https://bit.ly/2qaO9Td>. Acesso em: 19 mar. 2018.

2. GOOGLE Earth. Mountain View: Alphabet Inc., [201-]. Disponível em: <https://bit.ly/2nZn32T>. Acesso em: 25 out. 2018. 
Figura 2 - Imagem aérea de delimitação da gleba do Hospital de Dermatologia Sanitária do Paraná

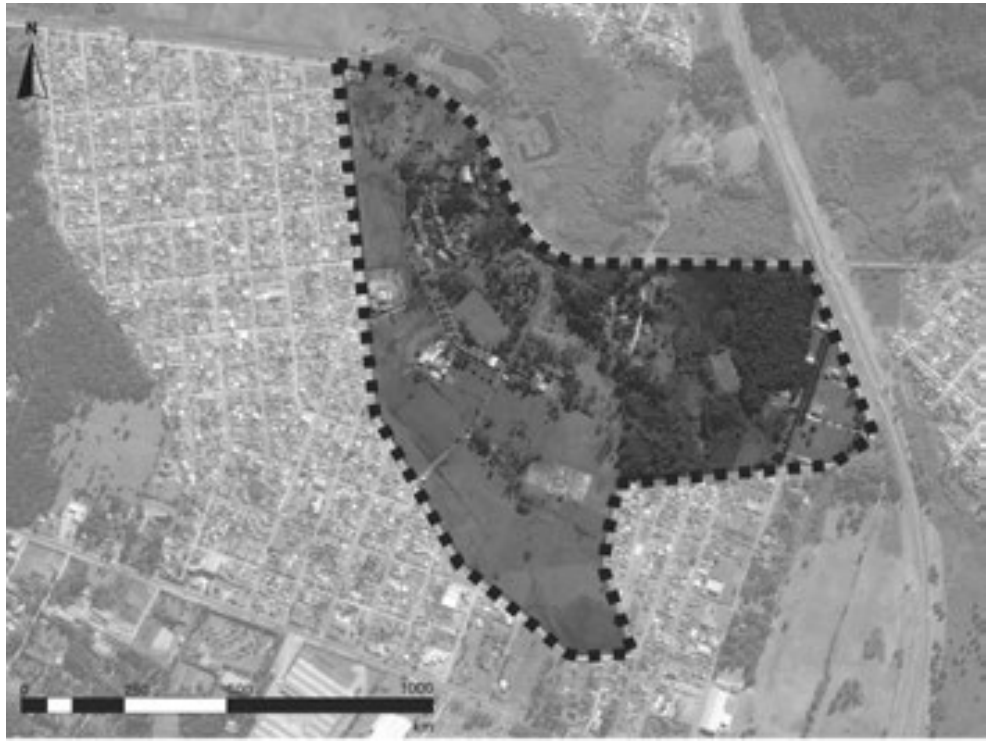

Fonte: Adaptada de Google Earth ${ }^{3}$

\section{Antecedentes da problemática: a construção do modelo}

A lepra foi, desde muito antigamente, considerada contagiosa, mutilante e incurável, causadora de rejeição e discriminação dos doentes por parte da sociedade (Brasil, 2004; Margoles; Del Rio; FrancoParedes, 2011; Sehgal, 2006). Para Monteiro (1998, p. 3), seu isolamento compulsório "contribuiu para que o estigma da hanseníase atingisse pessoas que nunca portaram a doença, como foi o caso das crianças sadias filhas de portadores". A quantidade mundial de contaminados é impossível de ser calculada para o último milênio (Leprosy..., 2018); todavia, Rodrigues e Lockwood (2011) citam que, no início do século XX, cerca de 250.000 novos casos eram detectados anualmente.

Até o princípio dos anos 1920, o isolamento dos leprosos não era obrigatório no Brasil; eles se dirigiam voluntariamente a modestos hospitais porque não tinham meios de sobrevivência (Schneider; Wadi, 2009). Todavia, ocorreram importantes mudanças no tratamento dos infectados, tanto com a instituição legal do internamento compulsório, pelo Decreto Federal $n^{0} 16.300$, de 31 de dezembro de 1923 (Brasil,
1923), quanto com a adoção do "modelo tripé", formado pelo leprosário (para os doentes), pelo dispensário (para os eventuais contagiados) e pelo preventório (para os filhos). Até o início da década de 1940, foram construídos vários hospitais-colônia para abrigar os atingidos pela moléstia. Começava, então, uma prática de segregação socioespacial (Lapchensk, 2017).

Ao cobrarem a necessidade do leprosário e ao definirem o leproso, impondo-lhe uma imagem negativa, os médicos e políticos incrementavam o medo do contágio, a impossibilidade da cura, a exigência de um espaço apropriado para internamento e tratamento dos doentes e o abandono da família e dos amigos, reforçando o medo social. (Silva, 2016, p. 325)

Mesmo com o avanço da medicina e a evolução do tratamento, a integração dos egressos ao meio se deu de forma precária, pois seu estigma ainda permanece (Carvalho, 2010). No final do século XIX, existiam três hospitais no Paraná, além de um abrigo, o Lazareto São Roque, que amparavam precariamente alguns portadores de lepra (Castro, 2005). No início dos 
anos 1900, foram construídas diversas unidades de saúde no estado. Por falta de conhecimento específico, algumas moléstias exigiam isolamento, como a tuberculose, a hanseníase e a demência. No entanto, não havia consenso em relação à terapêutica, sendo que alguns médicos prescreviam afastamento em nosocômios, enquanto outros acreditavam que colônias agrícolas apresentavam vantagens na socialização dos doentes, os quais poderiam trabalhar e produzir para seu próprio sustento (Marques; Larocca, 2009). Dessa forma, os hansenianos passaram a ser enclausurados e condenados à segregação social e espacial. Baseada nesses preceitos, ocorreu a construção do Sanatório São Roque, considerado, então, estabelecimento modelo, no qual os pacientes buscavam reconfigurar suas existências (Castro, 2005).

A partir da década de 1910, houve em Curitiba uma série de intervenções urbanas e sociais, executadas por um governo de situação financeira estável e com intenções de embelezar o espaço, disciplinar o uso do solo e controlar os habitantes - incluindo, nesse processo, a evolução do tratamento da hanseníase (Castro, 2005). Esses preceitos eram baseados em um ideal higienista de urbanização que, segundo Costa (2013), consistia numa “medicalização urbana”, na qual a cidade era idealizada a partir de propostas de salubridade, tendo a higiene como premissa. Dessa maneira, segundo Castro (2002), a construção dessas instituições de saúde pode ser considerada um dos pilares da intervenção urbanística nos moldes do higienismo, tendo afastado dos centros urbanizados o que poderia ameaçar a saúde da população, ou seja, as doenças e a pobreza, frequentemente associadas. Como consequência dos modelos então em voga, foram implantados diversos hospitais e colônias fora do perímetro urbano, como foi o caso do HDSPR (Schneider; Wadi, 2009). Nascimento e Rodrigues (2010) citam que sua nomenclatura foi alterada diversas vezes, como em 1939, quando passou a ser denominado Colônia São Roque (CSR); foi posteriormente chamado de Sanatório Colônia São Roque (SCSR), até que finalmente, em 1986, recebeu o nome atual.

Se, por um lado, o isolamento era considerado um castigo, por outro, era obrigação do Estado amenizar a situação dos pacientes. Nesse cenário, as colônias deveriam ser aprazíveis, confortáveis e plenas, de forma que os leprosos espontaneamente as procurassem, o que revela enfoque humanitário, voltado à tentativa de oferecimento de uma vida dita "normal" (Castro, 2005).

De acordo com Castro (2002), a ociosidade era inaceitável nessa época de valorização da atividade produtiva, e o trabalho era uma alternativa de controle e redenção de grupos sociais, especialmente criminosos, alienados e doentes. Marques e Larocca (2009, p. 7) reforçam que "ali o trabalho parecia estimular o processo de restituir a utilidade e a dignidade perdida após sucessivas rejeições e humilhações".

Assim, tais complexos reuniam, em um só lugar, as necessidades humanas de moradia, trabalho e lazer, afastando da sociedade certos indivíduos, que representavam riscos. Segundo Schneider e Wadi (2009), nesses locais, os asilados poderiam exercer normalmente diversas atividades, desde as mais pesadas até as relativas às enfermarias, como a ajuda no cuidado de outros doentes em pior estado. Os internos também podiam assistir a filmes e participar de rituais, bailes e festas religiosas, além de outras comemorações, mas havia normas cujo descumprimento levava a punições (Marques; Larocca, 2009).

Castro (2005) informa que o Hospital São Roque foi projetado pelo engenheiro civil Jorge Meissner, sendo proposto um isolamento humanitário. Assim, eram proporcionadas condições de moradia (dormitórios para enfermos e habitações para funcionários, médicos e familiares), trabalho (campos de produção agrícola, áreas para criação de animais, carpintaria, moinho e aviário, por exemplo) e diversão (salas de cinema e projeções, discoteca, quadra de futebol, cancha de bocha, biblioteca, locais para jogo de xadrez e bar, entre outros espaços), além de serviços de apoio (secretaria, departamentos de assistência social, psicológica, médica e funerária, cozinha, açougue, restaurantes, barbearia, lavanderia etc.). Também havia instalações de correio, telefone, água potável e energia elétrica e áreas de cunho espiritual (igreja e cemitério). Seguindo os preceitos do higienismo, o intuito era que o complexo fosse independente da cidade.

Os projetos arquitetônico e urbanístico adotaram como princípio a setorização bem marcada, com 
infraestrutura básica e aproveitamento da insolação, valorização da ventilação e controle mais efetivo do doente (Castro, 2005). A arquitetura - utilitária, simbólica, harmônica e sóbria - possuía formas simples e econômicas, sem ornamentações e excessos. A função, característica do movimento modernista, é evidente, apesar de não apresentar fortes traços de estilo. O conjunto principal é desenvolvido a partir de um corpo central (Figura 3), voltado às atividades administrativas, com espaços hierarquizados, delimitados e dispostos simetricamente, com circulação (aberturas e acessos) bem proporcionada em relação ao controle. Os pavilhões são destacados pela separação física, com ligações por meio de passarelas afastadas do alinhamento frontal.

Castro (2005, p. 21) explica que "a escolha do local foi feita a partir de critérios técnicos, sociais e econômicos", sendo fatores determinantes a presença da estrada de ferro que liga Curitiba ao litoral, o clima ameno, a existência de água em abundância devido aos mananciais em operação, o reduzido número de habitantes, a produtividade incipiente e o baixo preço da terra. Contudo, a valorização das características técnicas das propostas arquitetônicas e urbanísticas não foi suficiente para suplantar as dificuldades inerentes à rejeição social do empreendimento.

\section{Figura 3 - Vista panorâmica do Hospital de Dermatologia Sanitária do Paraná em 1926}

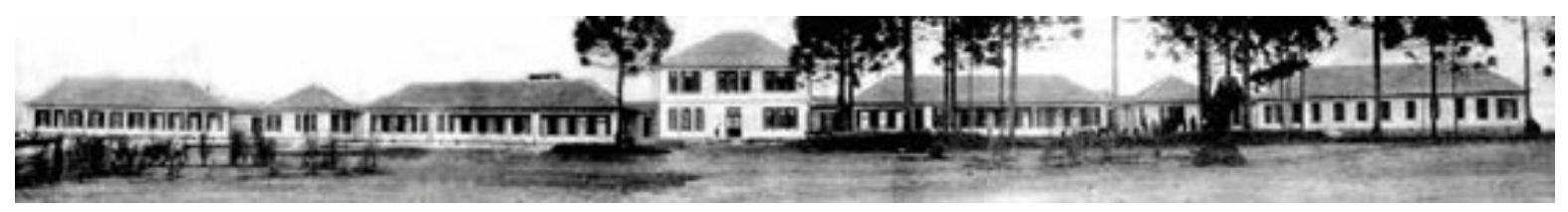

Fonte: Castro, 2005, p. 23

\section{Experiências com a lepra: a presença do estigma}

Sansaloni (2001) revela que a instituição funcionou por longo período como estrutura praticamente autossustentável - ou seja, como lugar onde o interno deveria morar, viver, tratar-se e morrer; o objetivo era afastar os doentes do cotidiano da sociedade para evitar a transmissão da moléstia, que, até então, causava pânico.

Como marca duradoura, o estigma carrega sentido social (Romero-Salazar et al., 1995). Para Goffman (2008, p. 6), trata-se de efetivo descrédito, defeito, fraqueza ou desvantagem, que "constitui uma discrepância específica entre a identidade social virtual e a identidade social real". Ou seja, o indivíduo deixa transparecer evidências de possuir atributos que o tornam diferente, como espécie menos desejável e pessoa má, perigosa ou fraca.

No caso da sua relação com a hanseníase, suas diversas justificativas ao longo do tempo foram fundamentais para o entendimento dos hospitais-colônia. Cientificamente, não foram encontradas explicações para vários estigmatizados cristãos no processo histórico, mas, para a religião, seu valor é considerável. Vale lembrar que o termo "lepra" (zarath) teve origem no Antigo Testamento, posteriormente traduzido por São Jerônimo, vertido para o grego com o sentido de "sujeira" e disseminado com significado de moléstia, castigo divino, desonra ou pessoa ruim/marginalizada (Sansaloni, 2001). Já no Novo Testamento, Mateus narra a cura do leproso como o primeiro milagre de Jesus. Por muito tempo, então, a doença foi transpassada pelo sentido da crença e pela manifestação do pecado. Dada a importância da teologia no reconhecimento da moléstia, vários leprosários eram conduzidos por congregações religiosas e dotados de capela e cemitério (Nascimento; Rodrigues, 2010), inclusive para assistência espiritual aos pacientes (Castro, 2005).

Um dos sentidos no qual se enquadra o estigma da hanseníase é referente às deformidades corporais que atingem seus portadores, com marcas permanentes, como perdas e alterações de membros, 
cegueira e manchas na pele, entre outras (Stremel et al., 2009). Conforme relata Goffman (2008), o não enquadramento de estereótipos criados pela sociedade reduz o diferente a pessoa estragada e diminuída. Porém, isso não se limita às relações teológicas e físicas, alcançando também as sociais, pois o processo de segregação começava com a rejeição do doente por parte da família e se agravava em meio à sociedade (Sansaloni, 2001), não obstante a capacidade de adaptação do homem no seu relacionamento com o mundo (Mello; Teixeira, 2012).

No caso do Hospital São Roque, Marques e Larocca (2009) relatam que os maquinistas, por exemplo, recebiam ordens expressas para fechamento das janelas e portas das locomotivas na sua transposição por Piraquara. Carvalho (2010) complementa que um vagão era reservado às pessoas doentes e que, durante as paradas do trem, eram fechados os que transportavam os passageiros sadios para prevenir contato com os enfermos.

A população de Piraquara aprendeu a conviver com os acometidos pela doença, pois era constituída, em grande parte, por imigrantes italianos, poloneses, ucranianos, portugueses e espanhóis, que conheciam a lepra em seus países (Sansaloni, 2001). No início, entretanto, mantinha-se um ideal de segregação dos internos, pois as comunidades locais restringiam sua circulação a determinados espaços. Castro (2005) comenta que, na época de inauguração, o estabelecimento atendia os requisitos para atendimento aos seus fins e possuía capacidade de acolher 600 pacientes, mas, como indica Carvalho (2010), chegou a abrigar 1,2 mil pessoas - tendo sido, inclusive, considerado um modelo pela sua concepção de colônia, configuração arquitetônica e preocupação humanitária. Como o isolamento não solucionou o problema da doença e não houve redução do número de infectados, a internação começou a ser questionada.

\section{Declínio dos ideais: a trajetória da segregação}

Ao final dos anos 1940, o tratamento da hanseníase com sulfona eliminou a necessidade de reclusão e desencadeou o processo de desativação dos antigos hospitais-colônia (Nascimento; Rodrigues, 2010).
Todavia, foi somente por intermédio do Decreto Federal $n^{0}$ 968, de 7 de maio de 1962, que o internamento obrigatório deixou de vigorar (Brasil, 1962).

Como consequência, houve redução das atividades nesses estabelecimentos de saúde e crescimento das ações ambulatoriais (Araújo; Oliveira, 2003). Muitos dos doentes que passaram ao regime semiaberto já não se adaptavam à vida anterior, além de portarem sequelas, como paralisia, cegueira e doenças mentais, que condicionaram a continuidade do seu isolamento. Entretanto, as mudanças institucionais vigentes à época provocaram reorientação de recursos para outros fins, provocando, inclusive, a degradação física de edificações desse tipo de hospital.

Para Olinto (2002), ultrapassando a categoria de doença, a lepra se relaciona com questões de impureza, mal e desordem, o que fazia com que seus portadores ficassem reclusos. De acordo com Goffman (2008), a pessoa estigmatizada nessa situação poderia facilmente estabelecer relações sociais cotidianas, mas suas características a afastavam das demais, impossibilitando a atenção para outros dos seus prováveis atributos. Nessas condições, adquiriam, involuntariamente, nova identidade, vinculada à enfermidade, num estatuto de doente comum, imaginário e coletivo, desprovido de singularidades e vivências particulares, determinando ainda suas vidas, seus afetos e seus companheiros (Marques; Larocca, 2009). Além disso, a moléstia tornava muitos de seus contagiados facilmente reconhecíveis, o que causava, entre eles, forte retração social (Sansaloni, 2001), como um tipo de segregação voluntária (Lapchensk, 2017).

São diversos os relatos de preconceito e discriminação na história dos doentes (Marques; Larocca, 2009). Muitos foram internados por ação da polícia ou outras formas igualmente violentas. No submundo da boemia, do alcoolismo e da prostituição, os internos, por meio de frequentes fugas, procuravam aproveitar o pouco tempo de vida que lhes restava, pois se tratava de um espaço de sociabilidade e solidariedade, um dos poucos ambientes nos quais eram bem aceitos (Sansaloni, 2001).

Embora antiga, a prática de segregação nesses hospitais encontrou, à época, respaldo científico e legal (Castro, 2002), pois, além de ser um meio de tratamento da hanseníase, mantinha o problema fora 
das cidades (Olinto, 2002). Dessa maneira, várias vidas foram (re)construídas nos complexos intramuros, a ponto de muitos internos permanecerem lá morando, mesmo após a eliminação da obrigatoriedade do isolamento oficial. Na prática, sentiam-se presos de si próprios e dos demais, pois o preconceito não havia terminado (Sansaloni, 2001), sendo frequentes suas dificuldades e rejeições em locais fora das dependências das colônias (Marques; Larocca, 2009).

No caso do HDSPR, essa segregação era evidente, com três estruturas urbanas independentes. A primeira, dentro dos muros do complexo, seguia a lógica específica do tratamento hospitalar, isolada de diversas funcionalidades urbanísticas; paralelamente, enfrentava a anteriormente citada degradação dos edifícios. A segunda, no entorno próximo, correspondia à forma de ocupação tradicional da cidade, com clara desvinculação territorial da anterior, apesar da sua marcante conexão com o hospital, pois abrigava residências de familiares dos doentes. A terceira, correspondente ao restante do tecido urbanizado, possuía semelhanças espaciais com a precedente, mas não comportava relacionamentos acentuados com as demais em função do estigma da doença. Na visão de Schneider e Wadi (2009), tanto a sociedade como o Estado podem ser responsabilizados pelas medidas segregacionistas, tornando possível, nos momentos de medo e crise, a percepção das formas de dinâmica social e das perdas de interação comunitária.

\section{Realidades do presente: a necessidade de inclusão}

A história individual e coletiva do ser humano está ligada ao seu convívio social, não podendo o desenvolvimento pessoal ser justificado, apenas, por características biológicas. Assim, essa compreensão perpassa o conjunto de diversos elementos e ações ao longo da vida do sujeito. Seu processo de interação com a sociedade desempenha papel fundamental na sua formação, pois o indivíduo necessita do estabelecimento de uma rede de contatos, com a finalidade de incrementar e construir novos conceitos (Mello; Teixeira, 2012).

Esse constante processo de aprendizagem não ocorre de forma isolada; ao contrário, representa um somatório de fatores, tanto biológicos quanto sociais e históricos (Vygotsky, 2009). Para Rogoff (1998), a apropriação participativa corresponde às maneiras como os cidadãos mudam a partir do seu envolvimento em diferentes atividades, num processo pessoal pelo qual, por meio do compromisso com determinada tarefa, controlam condições posteriores, preparadas pela própria participação em momentos prévios.

O mesmo autor afirma que, por meio desse tipo de apropriação, os envolvidos acumulam conhecimento e experiências anteriores, adquirindo preparo e discernimento para agir em situações futuras. Assim, estabelecem conexões conforme as necessidades da comunidade, assumindo-se como pessoas que se comunicam com outras e com quem são instauradas relações conforme seus interesses.

Como o ser humano não vive isolado, participa de diferentes ambientes, nos quais reúne seus contatos em torno de objetivos comuns. Assim, frequenta determinado meio por se sentir aceito e abrigado (Mello; Teixeira, 2012). Não obstante a afirmação de Zamparoni (2017, p. 15) de que, em termos gerais, "a doença que mais atenção recebeu nos debates médicos acerca do isolamento e segregação foi a lepra”, ainda se observa a necessidade de inclusão dos atingidos pela moléstia sob diversas óticas. As marcas físicas, psicológicas e sociais deixadas pela hanseníase muitas vezes prejudicaram a integração dos portadores da doença à sociedade, trazendo prejuízos aos sentimentos de acolhimento e pertencimento, a exemplo do ocorrido com os egressos da colônia em estudo.

Antecedido, entre 1961 e 1965, pela reforma geral dos pavilhões, além de outras melhorias (Sansaloni, 2001), no final da década de 1990 foi realizado um projeto que visava a revitalização do hospital para sua transformação no Parque da Saúde São Roque, com espaços para atividades recreativas, conferências e serviços laboratoriais, entre outros. Todavia, a proposta foi considerada inviável porque desconsiderava a permanência de muitos moradores e a continuidade de atendimento de diversos casos de hanseníase (Olinto, 2002). O HDSPR recebe, ainda hoje, contribuição material, cultural, religiosa, social e humanitária de irmãs e frades franciscanos, tanto dentro do hospital como no entorno. No processo de desocupação do 
complexo, o papel dos religiosos foi fundamental, pois, por seu intermédio, muitos dos egressos conseguiram reconstruir suas vidas (Marques; Larocca, 2009).

Lapchensk (2017) afirma que o progresso de Piraquara foi prejudicado pela demora, entre outros fatores, da pavimentação da rodovia de ligação de sua sede urbana a Curitiba, o que foi agravado pela imagem associada ao complexo penitenciário, a outros hospitais de isolamento e, especialmente, ao São Roque. Sansaloni (2001) complementa que, por muitas vezes, os hansenianos foram colocados no mesmo nível de detentos em diversos contextos de afirmações preconceituosas.

Atualmente, o hospital, de propriedade do estado do Paraná, opera na sua capacidade mínima, mas desenvolve atividades de uso público, como a Capelania São Roque e o cemitério, cuja administração foi transferida à municipalidade. Lapchenk (2017) alerta que é possível a travessia da gleba sem ser necessária, em alguns trechos, a identificação do transeunte. Todavia, para alguns setores, há portarias cuja transposição é sujeita a autorização específica.

Em termos urbanísticos, a Avenida Brasília, que atravessa a gleba do hospital e representa seu principal acesso, configura um "caminho", segundo a classificação dos cinco elementos de identidade urbana proposta por Lynch (2011). O terreno, caracterizado, em parte, como "bairro", é margeado por claros "limites" - como, ao sul, a PR415, ao norte, a ferrovia de ligação entre Curitiba e Paranaguá (a qual transporta, com frequência, turistas ao litoral paranaense) e, a leste, o rodoanel Contorno Leste. Ainda segundo categorização do mesmo autor, o cruzamento da linha férrea com a via pode ser interpretado como "nó" e o edifício principal como "marco".

Há, portanto, em escala local, estruturação urbana individualizada. No entorno, existe um espaço "periférico" de exclusão social, no qual, na década de 1940, foram construídos o presídio estadual e o Hospital Psiquiátrico Adauto Botelho, aumentando o preconceito em relação ao município (Nascimento; Rodrigues, 2010). À época, a concentração do comércio e dos eventos festivos ocorria no centro da sede municipal, com reduzida comunicação viária acontecendo por meio do trem ou da precária Estrada do Encanamento. Essas condições revelam que, mesmo inconscientemente, o município era marginalizado (Lapchensk, 2017).

Na década de 196o, já existiam vários pacientes em estágio controlado da doença morando em bairros próximos do hospital (Sansaloni, 2001). Hoje, muitos dos egressos se encontram nas três localidades do entorno (Jardins Esmeralda, Primavera e Santa Mônica) (Figura 4), ainda que, de maneira geral, não tenha havido preocupação com suas necessidades sociais, econômicas ou físicas (Stremel et al., 2009).

Atualmente, o local representa um entrave ao desenvolvimento do município, ao mesmo tempo em que guarda marcas do início da formação dos bairros do entorno (Lapchensk, 2017). Algumas áreas acumulam problemas para a região, pois o abandono torna determinados locais potencialmente inseguros, como é o caso do espaço da antiga vila de funcionários do hospital. No terreno, existe um conjunto com relativo potencial paisagístico, formado, em especial, por remanescentes florestais e um lago. A existência de diversos exemplares de espécies vegetais invasoras e a eutrofização do lago evidenciam o atual estado de descuido do patrimônio (Figura 5). A gleba, que já serviu como relevante área de lazer e atendimento a diversas famílias, inclusive de outras regiões, encontra-se inerte em meio à gama de necessidades de uma população carente dos mais diversos equipamentos e serviços urbanos (Lapchensk, 2017).

Vale lembrar que, para Lynch (2011), a cidade é uma construção em grande escala, em constante mutação, cuja imagem está impregnada de memórias e significados e na qual as pessoas e suas atividades são tão importantes quanto suas partes físicas. As novas características são adquiridas em constante sobreposição de tempos vividos (Hardt; Hardt, 2007), até a formatação atual do tecido urbano. No caso em estudo, esse processo gerou fragmentação territorial e estabeleceu fronteiras, tanto simbólicas e físicas quanto temporais e espaciais (Aguiar, 2014). Esses fatos ilustram o fenômeno de a sociedade ser, simultaneamente, produto e agente produtor do espaço, uma vez que, por relações sociais, os cidadãos reescrevem cotidianamente o tecido urbanizado, alterando contextos materiais e históricos pela impressão de novas marcas na paisagem e na sociedade (Medeiros, 2015). 
Figura 4 - Imagem aérea de configuração urbana do entorno do Hospital de Dermatologia Sanitária do Paraná

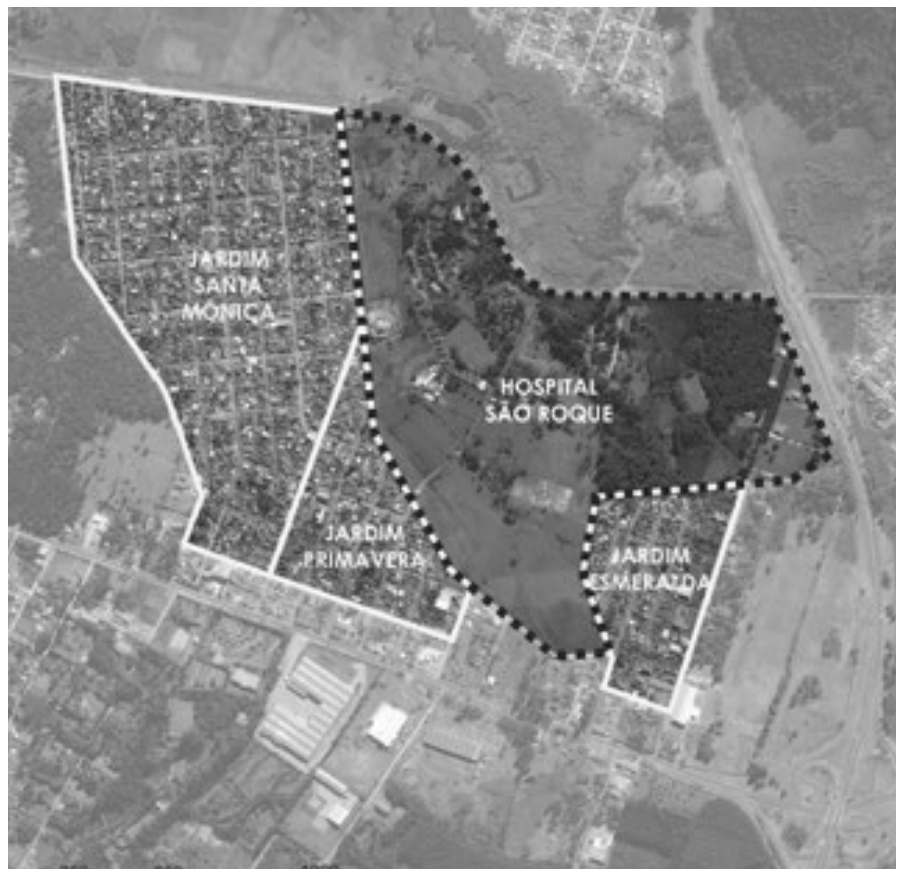

Fonte: Adaptada de Google Earth ${ }^{4}$ e Piraquara ${ }^{5}$

Figura 5 - Vistas do estado de abandono da gleba do Hospital de Dermatologia Sanitária do Paraná

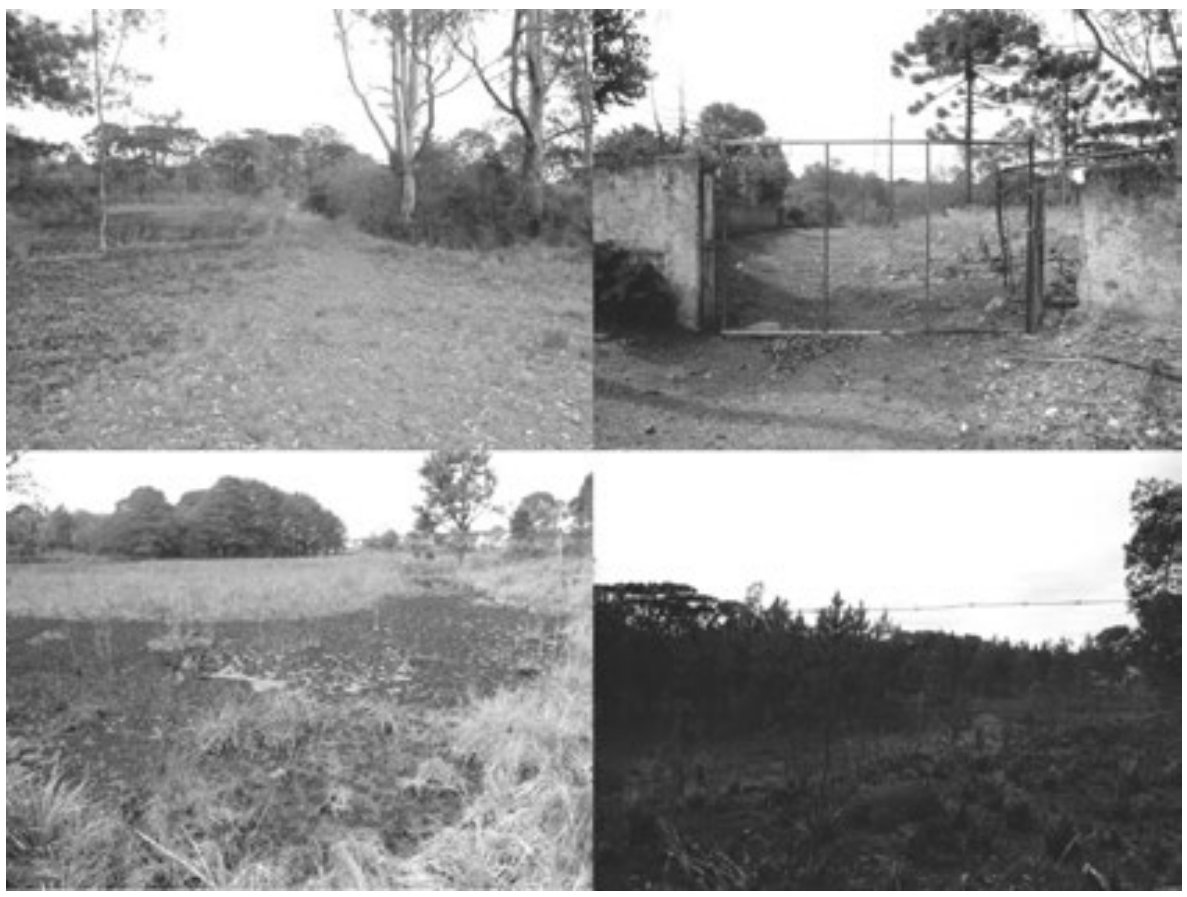

4 GOOGLE Earth. Mountain View: Alphabet Inc., [201-]. Disponível em: <https://bit.ly/2nZn32T>. Acesso em: 25 out. 2018.

5 PIRAQUARA. Prefeitura Municipal. Mapas. Piraquara, [20--]. Disponível em: 〈https://bit.ly/2Rhiev0>. Acesso em: 3 ago 2017. 
Briso (2015) ressalta que o Poder Público se comprometeu a manter os hospitais-colônia enquanto houvesse residentes e que o preconceito histórico é uma das causas de seu relativo abandono. No país, remanescem 33 unidades da época de reclusão compulsória, todas sujeitas a inúmeras dificuldades, a exemplo da desassistência a seus internos, deterioração dos seus imóveis e insuficiência de recursos para atendimento dos necessitados (Machado, 2004). Vieira (2016) julga inadmissível essa situação, especialmente em uma conjuntura nacional de crise institucional e financeira, notadamente no setor de saúde. Princípios do Movimento de Reintegração das Pessoas Atingidas pela Hanseníase (Morhan) propõem que as ex-colônias remanescentes no país sejam declaradas como patrimônio da humanidade, com vistas tanto à preservação da memória dos hospitais quanto à divulgação de informações sobre o período de internamento compulsório (Vieira, 2016).

Como corolário, depreende-se a essencialidade da cidade viva, segura, sustentável e saudável, segundo o que preconiza Gehl (2014), bem como justa e diversificada, além de outros preceitos defendidos por Rogers e Gumuchdjian (2016), somente passíveis de concretização a partir da definição de políticas públicas inclusivas e integradas em diferentes campos de atuação governamental, com destaque, para o caso estudado, àquelas referentes ao relacionamento de questões sociais e sanitárias com soluções espaciais e urbanísticas.

\section{Considerações finais}

Os antecedentes de uma doença de resultados traumáticos ao longo de quase toda a história da humanidade levaram à construção de um modelo hospitalar para internamento compulsório, como é o caso do HDSPR. Se foi útil à época, esse tipo de estabelecimento de saúde também foi questionado em reduzido espaço de tempo, em função tanto das inovações da ciência quanto das novas concepções de tratamento, dentre outras causas. Contudo, as experiências realizadas nesse âmbito reforçaram os efeitos deletérios da presença do estigma da moléstia, que, em parte, ainda permanecem no âmago da sociedade.
Por outro lado, os retrocessos provocados pelas descaracterizações daquele modelo são principalmente relacionados a uma trajetória de segregação, englobando desde vertentes sociais e territoriais até cenários espaciais e urbanísticos. Em qualquer dessas realidades, conclui-se pela premente necessidade de inclusão socioespacial e intraurbana. $O$ objeto estudado exemplifica claramente o caso de um componente segregado no primeiro âmbito e segregador no segundo, o que torna a resolução da problemática ainda mais complexa, especialmente ao se considerar sua impregnação histórica. Em uma situação cercada de prementes demandas, é inadmissível a existência de um patrimônio público em estado de abandono, ainda mais com seu passado tão carregado de significados. Esse é apenas um dentre vários exemplos no país.

Nessa perspectiva, em conjunto com a adoção de estratégias mundiais para controle geral da enfermidade e nacionais para melhoria das condições dos hospitais-colônia, há que se atentar para percepções e anseios dos atores diretamente envolvidos no processo - pretérito, atual e futuro -, bem como para suas consequências, a fim de embasar diretrizes democráticas de saúde. Paralelamente, deve ser efetivado o rompimento das barreiras - reais e imaginárias - entre complexos sanitários estigmatizados e as cidades às quais estão relacionados, não somente pela constituição de políticas públicas específicas de gestão local e urbana, mas também pela garantia de suas permanências memoriais e patrimoniais. Assim, há, por um lado, a perspectiva de não repetição de medidas de exclusão e, por outro, a possibilidade de implementação de ações de inclusão, em nova forma de profilaxia reversa: políticas públicas de saúde associadas a diretrizes de gestão de cidades.

\section{Referências}

AGUIAR, D. Permeabilidade urbana: a urbanização do cais. Drops, São Paulo, v. 14, abr. 2014. Disponível em: <https://bit.ly/2OTburC>. Acesso em: 7 dez. 2017.

ARAÚJO, R. R. D. F.; OLIVEIRA, M. H. P. A

irregularidade dos portadores de hanseníase ao serviço de saúde. Hansenologia Internationalis, Bauru, v. 28, n. 1, p. 71-78, 2003. 
BRASIL. Decreto Federal $n^{0} 16.300$, de 31 de dezembro de 1923. Approva o regulamento do Departamento Nacional de Saúde Pública. Coleção de Leis do Brasil, Rio de Janeiro, 31 dez. 1923. Disponível em: <https:// bit.ly/2reFSfP $>$. Acesso em: 25 out. 2018.

BRASIL. Decreto Federal no 968, de 7 de maio de 1962. Baixa normas técnicas especiais para o controle da lepra no país e dá outras providências. Diário Oficial da União, Brasília, DF, 9 maio 1962. Disponível em: <https://bit.ly/2ObhqXK>. Acesso em: 25 out. 2018.

BRASIL. Ministério da Saúde. Hanseníase: atividades de controle e manual de procedimentos. 2. ed. Brasília, DF: Secretaria de Políticas de Saúde, 2004.

BRISO, C. B. Vidas ainda aprisionadas em um antigo leprosário. O Globo, Rio de Janeiro, 24 abr. 2015. Disponível em: <https://glo.bo/2z3MfYN>. Acesso em: 3o jun. 2016.

CARVALHO, J. Hanseníase não exige mais isolamento. Tribuna PR, Curitiba, 30 maio 2010. Disponível em: <https://bit.ly/2D3HW3V >. Acesso em: 25 jan. 2018.

CASTRO, E. A. São Roque: um exílio: uma análise do papel do Hospital São Roque (Piraquara/PR) na história da hanseníase no Paraná. 2002. Monografia (Especialização em Análise Ambiental) - Universidade Federal do Paraná, Curitiba, 2002.

CASTRO, E. A. A arquitetura do isolamento em Curitiba na República Velha. Curitiba: Maxigráfica, 2004 .

CASTRO, E. A. O leprosário São Roque e a modernidade: uma abordagem da hanseníase na perspectiva da relação espaço-tempo. 2005. Tese (Doutorado em Geografia) - Universidade Federal do Paraná, Curitiba, 2005.

COSTA, M. C. L. O discurso higienista definindo a cidade. Mercator, Fortaleza, v. 12, n. 29, p. 51-67, 2013.

ENGEL, M. G. Os delírios da razão: médicos, loucos e hospícios (Rio de Janeiro, 1830-1930).

Rio de Janeiro: Fiocruz, 2001.

FELDMAN-BIANCO, B. Introdução. In: FELDMANBIANCO, B. (Org.). Antropologia das sociedades contemporâneas: métodos. 2. ed. São Paulo: Editora Unesp, 2010. p. 7-45.

GEHL, J. Cidades para pessoas. Tradução de Anita Di Marco. 2. ed. São Paulo: Perspectiva, 2014.
GOFFMAN, E. Estigma: notas sobre a manipulação da identidade deteriorada. Tradução de Mathias Lambert. 4. ed. reimpr. Rio de Janeiro: LTC, 2008.

HARDT, L. P. A.; HARDT, C. Contexto histórico de intervenção na paisagem e espaços urbanos.

Paisagem e Ambiente: Ensaios, São Paulo, n. 23, p. 101107, 2007.

LAPCHENSK, A. F. Paisagem segregada: origens e consequências no município de Piraquara, Paraná. 2017. Dissertação (Mestrado em Gestão Urbana) Pontifícia Universidade Católica do Paraná, Curitiba, 2017.

LEPROSY. World Health Organization, Geneva, 9 fev. 2018. Disponível em: <https://bit.ly/1xfOVI2>. Acesso em: 27 jan. 2018.

LIMA, N. T.; FONSECA, C. M. O.; HOCHMAN, G. A saúde na construção do Estado nacional no Brasil: reforma sanitária em perspectiva histórica. In: LIMA, N. T. et al. (Org.). Saúde e democracia: história e perspectivas do SUS. 3. reimp. Rio de Janeiro: Fiocruz, 2005. p. 27-58.

LYNCH, K. A imagem da cidade. Tradução de Jefferson Luiz Camargo. 3. ed. São Paulo: WMF Martins Fontes, 2011.

MACHADO, K. Em pauta, a reestruturação dos antigos hospitais-colônia. Jornal do Movimento de Reintegração das Pessoas Atingidas pela Hanseníase, Rio de Janeiro, v. 22, n. 40, p. 4-8, 2004.

MARGOLES, L.; DEL RIO, C.; FRANCO-PAREDES, C. Leprosy: a modern assessment of an ancient neglected disease. Boletín Médico del Hospital Infantil de México, Ciudad de México, v. 68, n. 2, p.110-116, 2011.

MARQUES, V. R. B.; LAROCCA, L. M. "Eu não tava acostumada com gente sem braço, sem perna...”: com a palavra ex-doentes do mal de Hansen. In: SIMPÓSIO NACIONAL DE HISTÓRIA, 25., 2009, Fortaleza. Anais... Fortaleza: Associação Nacional de História, 2009. p. 1-9. CD-ROM.

MEDEIROS, I. H. Transporte sobre trilhos em Belo Horizonte: trilhas em um palimpsesto urbano. Espinhaço, Diamantina, v. 4, n. 1, p. 35-42, 2015. MELLO, E. F. F.; TEIXEIRA, A. C. A interação social descrita por Vigotski e a sua possível ligação com a aprendizagem colaborativa através das tecnologias 
de rede. In: SEMINÁRIO DE PESQUISA EM

EDUCAÇÃO DA REGIÃO SUL, 9., 2012, Caxias do Sul.

Comunicações... Caxias do Sul: Associação Nacional de Pós-Graduação e Pesquisa em Educação, 2012.

p. 1-15.

MONTEIRO, Y. N. Violência e profilaxia: os preventórios paulistas para filhos de portadores de hanseníase. Saúde e Sociedade, São Paulo, v. 7, n. 1, p. 3-26, 1998.

NASCIMENTO, M. S.; RODRIGUES, Z. L. O Lacen e a importância dos dados laboratoriais de baciloscopias para confirmação do diagnóstico, classificação de casos, acompanhamento e alta do paciente com hanseníase. Intersaberes, Curitiba, v. 5, n. 10, p. 285312, 2010.

OLINTO, B. A. Pontes e muralhas: diferença, lepra e tragédia (Paraná início do século XX). 2002. Tese (Doutorado em História) - Universidade Federal de Santa Catarina, Florianópolis, 2002.

RODRIGUES, L. C.; LOCKWOOD, D. N. J. Leprosy now: epidemiology, progress, challenges, and research gaps. The Lancet Infectious Diseases, London, v. 11, n. 6, p. 464-470, 2011.

ROGERS, R.; GUMUCHDJIAN, P. Cidades para um pequeno planeta. Tradução de Anita Regina Di Marco. 2. ed. São Paulo: Gustavo Gili, 2016.

ROGOFF, B. Observando a atividade sociocultural em três planos: apropriação participatória, participação guiada e aprendizado. In: WERTSH, J. V.; DEL RIO, P.; ALVAREZ, A. (Ed.) Estudos socioculturais da mente. Tradução de Maria da Graça Gomes Paiva e André Rossano Teixeira Camargo. Porto Alegre: ArtMed, 1998. p. 123-142.

ROMERO-SALAZAR, A. et al. El estigma en la representación social de la lepra. Cadernos de Saúde Pública, Rio de Janeiro, v. 11, n. 4,

p. 535-542, 1995 .

SANSALONI, F. Cidadela de proscritos: sanatório colônia São Roque nas décadas 1960-1970. 2001. Monografia (Graduação em História) - Universidade Federal do Paraná, Curitiba, 2001.

SCHNEIDER, S. D.; WADI, Y. M. Lepra: representações da doença e dos doentes através de discursos médicocientíficos e governamentais. In: CONGRESSO INTERNACIONAL DE HISTÓRIA, 4., 2009, Maringá.
Comunicações... Maringá: Universidade Estadual de Maringá, 2009.

SEHGAL, A. Deadly diseases and epidemics: leprosy. New York: Chelsea House, 2006.

SILVA, L. F. Filantropia e política de assistência às famílias de doentes de lepra em Goiás, 1920-1962. História, Ciências, Saúde: Manguinhos, Rio de Janeiro, v. 23, n. 2, p. 321-340, 2016.

SMITH III, T. H. A monument to Lazarus: the leprosy hospital of Rio de Janeiro. História, Ciências, Saúde:

Manguinhos, Rio de Janeiro, v. 10, p. 143-16o, 2003. Suplemento 1.

STREMEL, N. N. et al. Cidadãos asilados egressos do Hospital de Dermatologia Sanitária do Paraná: funcionalmente como estão? Cadernos de Saúde Coletiva, Rio de Janeiro, v. 17, n. 1, p. 25-38, 2009.

VAN VELSEN, J. A análise situacional e o método de estudo de caso detalhado. In: FELDMAN-BIANCO, B. (Org.). Antropologia das sociedades contemporâneas: métodos. 2. ed. São Paulo: Editora Unesp, 2010. p. 345374 .

VENANCIO, A. T. A. Da colônia agrícola ao hospitalcolônia: configurações para a assistência psiquiátrica no Brasil na primeira metade do século XX. História, Ciências, Saúde: Manguinhos, Rio de Janeiro, v. 18, p. 35-52, dez. 2011. Suplemento 1.

VIEIRA, I. ONG critica abandono de ex-colônias para pessoas com hanseníase no Rio. Agência Brasil, Brasília, DF, 29 out. 2016. Disponível em: <https://bit. ly/2elwhxt>. Acesso em: 14 nov. 2017.

VYGOTSKY, L. S. A construção do pensamento e da linguagem. Tradução de Paulo Bezerra. 2. ed. São Paulo: WMF Martins Fontes, 2009.

ZAMPARONI, V. Lepra: doença, isolamento e segregação no contexto colonial em Moçambique. História, Ciências, Saúde: Manguinhos, Rio de Janeiro, v. 24, n. 1, p. 13-39, 2017.

\section{Contribuição das autoras}

De forma conjunta, ambas as autoras contribuíram em todas as fases de desenvolvimento da pesquisa e de elaboração do texto.

Recebido: 14/09/2018

Aprovado: 17/10/2018 